Research Paper

\title{
Impact of clinical and pathological factors on local recurrence after breast-conserving treatment: CT-based localization for a tumor bed boost yielded better local control when compared with a surgical scar
}

\author{
Lize Wang, Jinfeng Li, Tianfeng Wang, Yuntao Xie, Zhaoqing Fan, Yingjian He, Tao Ouyang ${ }^{\bowtie}$ \\ Key Laboratory of Carcinogenesis and Translational Research (Ministry of Education/ Beijing), Breast Cancer Center, Peking University Cancer Hospital \& \\ Institute, Beijing, China \\ $\square$ Corresponding author: Tao Ouyang, Key Laboratory of Carcinogenesis and Translational Research (Ministry of Education/ Beijing), Breast Center, Peking \\ University Cancer Hospital \& Institute, Beijing 100142, China. E-mail: ouyanghongtao@263.net. \\ (C) Ivyspring International Publisher. This is an open access article distributed under the terms of the Creative Commons Attribution (CC BY-NC) license \\ (https://creativecommons.org/licenses/by-nc/4.0/). See http://ivyspring.com/terms for full terms and conditions.
}

Received: 2018.07.05; Accepted: 2018.10.30; Published: 2019.01.01

\begin{abstract}
Background: We investigated the effects of risk factors on the incidence of local recurrence (LR) in patients who underwent breast-conserving treatment (BCT) for primary breast cancer at a single institution in China from 1999 to 2011.

Methods: Patient outcomes were compared with respect to LR, ipsilateral breast tumor recurrence (IBTR), distant disease-free survival (DDFS), and disease-free survival (DFS). Additionally, the risk factors for relapse after BCT were studied.

Results: The 2028 patients with invasive breast cancer included in this study were followed for a median of 95 months, during which the 8-year LR, IBTR, DDFS, and DFS rates were $2.6 \%, 3.0 \%$, $93.7 \%$, and $91.3 \%$, respectively. Lymph node involvement, the human epidermal growth factor receptor 2 (HER2) status, and the use of computed tomography (CT) information during boost field planning were identified as significant predictors of LR and IBTR. Notably, use of the surgical scar for tumor bed identification during boost field planning was associated with a higher adjusted risk of LR, compared with the use of CT. By contrast, the neoadjuvant chemotherapy (NAC) was not an independent predictor of LR (hazard ratio of no NAC vs. NAC, $0.63 ; 95 \%$ confidence interval, $0.33-1.19 ; P=0.157)$. In a multivariate analysis, the age at diagnosis, tumor diameter, lymph node involvement, HER2-positive status, and use of CT information during boost field planning were identified as significant factors affecting DFS.

Conclusions: The use of $C T$ information during boost field planning could reduce the risk of LR among patients undergoing BCT. Neoadjuvant and adjuvant treatments for breast cancer did not show the significant difference in respect to the outcome of $L R$.
\end{abstract}

Key words: Breast cancer; Breast-conserving treatment; Local recurrence; Ipsilateral breast tumor recurrence; Distant disease-free survival

\section{Introduction}

To date, randomized trials have demonstrated similar survival rates between patients with primary breast cancer who underwent breast-conserving treatment $(\mathrm{BCT})$ or modified radical mastectomy (MRM) [1, 2]. However, recent tumor registry data have suggested the potential superiority of BCS when combined with RT [3], consistent with the results of a Chinese study [4]. Data regarding the addition of neoadjuvant chemotherapy (NAC) have been less consistent. One study found that tumor downsizing 
via NAC was associated with a higher risk of local recurrence (LR) after BCT [5].

In this report, we summarize the results of a long-term follow-up analysis of patients who underwent $\mathrm{BCT}$ for primary breast cancer at a single institution. Briefly, this analysis focused on the outcomes of LR, ipsilateral breast tumor recurrence (IBTR), distant disease-free survival (DDFS), and disease-free survival (DFS). Furthermore, we aimed to quantify the associations of clinical and pathological characteristics with LR among Chinese women with primary breast cancer who underwent $\mathrm{BCT}$.

\section{Methods}

\section{Patient characteristics}

Data on 6323 women with primary breast cancer who underwent BCT or MRM between December 1999 and April 2011 were obtained from a database created and managed by our hospital. Women who were diagnosed with primary invasive breast cancer and underwent BCS followed by radiotherapy were included in this study.

The patients' clinical, pathological, and treatment information was obtained from the database of the Breast Cancer Center, including the age at diagnosis, axillary lymph node spread, hormone receptor status, use of NAC, maximal tumor diameter, human epidermal growth factor receptor 2 (HER2) status, preoperative magnetic resonance imaging (MRI), date of surgery, and use of computed tomography (CT) information during boost field planning. We note that MRI has been used at our institution for the preoperative staging of the affected breast in women with newly diagnosed breast cancer since 2007.

\section{Surgical procedures and adjuvant therapy}

Ultrasound localization was used preoperatively to maximize the probability of complete tumor removal. Tumors were marked with skin tattoos prior to the administration of NAC. The closed-cavity surgical procedure included resection of the primary tumor with a surrounding normal tissue margin of at least $0.5-1.0 \mathrm{~cm}$, which was determined according to the surgeon's observation and the results of intraoperative frozen section evaluations. Glandular reshaping was based on the ratio of breast size to tumor resection volume.

The operative specimens were oriented using 1-4 sutures marking the medial, lateral, superior, and inferior surfaces. Each separate, additional shaved margin was labeled with a suture at the new section. Shaved margins were obtained for all patients at the time of the original surgery. Each specimen was sliced into sections that were tangent to each labeled margin from the exterior of the tumor mass. If a positive margin was identified, additional tissue was excised during the same surgery according to the patient's surgical cavity, with the ultimate aim of obtaining a negative margin. The final margin status was determined by examining permanent paraffin-embedded sections shaved from the interior of the frozen section, after which no additional margin slices were obtained from the residual specimen. Furthermore, sentinel lymph node biopsy with a 99mTc-labeled rituximab tracer was introduced at our institution in 2005. Patients with positive sentinel lymph nodes underwent complete staging with axillary lymph node dissection.

In addition to surgical excision of the primary tumor with a negative margin, all patients were administered radiotherapy using tangential fields directed at the intact breast. Before 2007 at Peking University Cancer Hospital, surgical scar was used to identify the tumor bed to determine the boost area. Since 2007, CT-based treatment planning for patients with breast cancer has been routinely applied and used to define the boost fields.

The principles of adjuvant chemotherapy (or NAC) and adjuvant hormonal therapy was consistent with the guidelines of the National Comprehensive Cancer Network and St. Gallen. NAC was defined as at least two cycles of preoperative chemotherapy, which comprised anthracycline- and/or taxane-based regimens.

\section{Recurrence and distant metastasis}

The primary endpoints of this study were LR and IBTR. The secondary endpoints were DDFS and DFS. All patients underwent annual mammography screenings, as well as ultrasonography of the bilateral breasts (or the remaining breast in cases of total mastectomy) and lymphatic regions every 6 months for 5 years postoperatively and annually thereafter. Other diagnostic studies were performed at the discretion of the referring physician. An IBTR was classified as a definite LR if it was located within $3 \mathrm{~cm}$ of the original primary tumor bed (i.e., within the same quadrant), was determined to be of the same histological type, and had the same or a higher grade. DDFS was defined as the time interval from surgery to distant metastases, while DFS was defined as the time interval from surgery to local, regional, or distant treatment failure.

\section{Statistical analysis}

Patient characteristics were compared between subtypes using the chi-square test. Survival probabilities were estimated using the Kaplan-Meier method. Patient and tumor characteristics were 
individually analyzed using the log-rank test to determine the effect of each variable. A Cox proportional hazards regression was used to assess the independent associations of several variables with LR, IBTR, DDFS, and DFS. Hazard ratios (HRs) and their 95\% confidence intervals (95\% CIs) were estimated using a Cox model with a backward stepwise method. All reported $P$ values were two-sided, and a value of $<0.05$ was considered statistically significant. All statistical analyses were performed using SPSS 17.0 (IBM, Armonk, NY, USA).

\section{Results}

Between December 1999 and April 2011, a total of 2028 patients $(32.1 \%)$ with invasive breast cancer who underwent BCT were enrolled; among them, postoperative follow-up records were unavailable for 24 patients. The median follow-up duration after definitive surgery was 95 months (range, 5-193 months). However, 103 patients $(5.0 \%)$ were lost to follow-up and were recorded as having a follow-up duration of $<60$ months. The 8-year LR, IBTR, DDFS, and DFS rates were $2.6 \%(95 \% \mathrm{CI}, 1.9-3.3 \%), 3.0 \%$ (95\% CI, 2.3-3.7\%), 93.7\% (95\% CI, 92.6-94.8\%), and 91.3\% (95\% CI, 90.0-92.6\%), respectively. Table 1 presents the clinical characteristics of the patient cohort.

Table 1. Patient characteristics

\begin{tabular}{lll}
\hline & Patients & \\
\cline { 2 - 3 } & Risk factor & $\mathrm{n}(\%)$ \\
\hline Age at diagnosis(years) & $\leq 40$ & $515(25.7 \%)$ \\
& $>40$ & $1489(74.3 \%)$ \\
Size $(\mathrm{cm})$ & $\leq 2$ & $1195(59.6 \%)$ \\
Hormone receptor & $>2$ & $809(40.4 \%)$ \\
& Negative & $469(23.4 \%)$ \\
& Positive & $1470(73.4 \%)$ \\
Axillary lymph node & unknown & $65(3.2 \%)$ \\
status & Negative & $750(37.4 \%)$ \\
Her-2 status & Positive & $1254(62.6 \%)$ \\
& Negative & $1489(74.3 \%)$ \\
Neoadjuvant & Positive & $271(13.5 \%)$ \\
chemotherapy & unknown & $244(12.2 \%)$ \\
Boost design method & Yes & $1079(53.8 \%)$ \\
& No & $925(46.2 \%)$ \\
Year of surgical & Surgical scar & $699(34.9 \%)$ \\
& CT-bed & $1305(65.1 \%)$ \\
preoperative MRI & $1999-2007.1 .1$ & $752(37.5 \%)$ \\
& 2007- & $1252(62.5 \%)$ \\
\hline & No & $1045(52.1 \%)$ \\
\hline & Yes & $959(47.9 \%)$ \\
\hline
\end{tabular}

\section{Local control}

The clinical and pathological factors found to associate with the 8-year LR rate are presented in Table 2. Lymph node involvement, a HER2-positive status, and the use of CT information during boost field planning were significantly associated with LR according to both log-rank tests and a Cox multivariate analysis (Figs. 1, 2, 3). Specifically, women with a HER2-positive status had a higher risk of LR, compared to those with a HER2-negative status (HR of HER2-positive vs. -negative, 1.67; 95\% CI, 1.24-2.26; $P=0.001)$. Furthermore, the use of CT for tumor bed identification during boost field planning was associated with a significant improvement in the local control rate, compared to the use of surgical scars (HR of CT vs. surgical scar, $0.24 ; 95 \% \mathrm{CI}$, 0.12-0.47; $P<0.001$ ) (Table 2).

Table 2. Univariate and multivariable analysis for local recurrence

\begin{tabular}{|c|c|c|c|c|}
\hline \multirow[t]{2}{*}{ Factors } & \multicolumn{2}{|c|}{ Univariate analysis } & \multicolumn{2}{|c|}{ Multivariate analysis } \\
\hline & 8-year LR rate & $P^{*}$ & $H R^{* *}(95 \% \mathrm{CI})$ & $P^{* * *}$ \\
\hline \multicolumn{5}{|l|}{ Age (years) } \\
\hline$\leq 40$ & $3.2 \% \pm 1.5 \%$ & 0.173 & 1 & 0.292 \\
\hline$>40$ & $2.3 \% \pm 0.7 \%$ & - & $0.72(0.39-1.32)$ & - \\
\hline \multicolumn{5}{|l|}{ Size $(\mathrm{cm})$} \\
\hline$\leq 2$ & $1.8 \% \pm 0.7 \%$ & 0.115 & 1 & 0.562 \\
\hline$>2$ & $3.7 \% \pm 1.3 \%$ & - & $1.19(0.66-2.13)$ & - \\
\hline \multicolumn{5}{|l|}{$\begin{array}{l}\text { Hormone } \\
\text { receptor }\end{array}$} \\
\hline Negative & $3.7 \% \pm 1.7 \%$ & 0.070 & 1 & 0.519 \\
\hline Positive & $2.3 \% \pm 0.7 \%$ & - & $0.82(0.44-1.51)$ & - \\
\hline \multicolumn{5}{|l|}{$\begin{array}{l}\text { Axillary } \\
\text { lymph node }\end{array}$} \\
\hline Negative & $1.4 \% \pm 0.7 \%$ & $<0.001$ & 1 & 0.006 \\
\hline Positive & $4.5 \% \pm 1.5 \%$ & - & $2.27(1.27-4.01)$ & - \\
\hline \multicolumn{5}{|l|}{ Her-2 status } \\
\hline Negative & $2.3 \% \pm 0.7 \%$ & $<0.001$ & 1 & 0.001 \\
\hline Positive & $6.5 \% \pm 2.9 \%$ & - & $1.67(1.24-2.26)$ & - \\
\hline \multicolumn{5}{|l|}{$\begin{array}{l}\text { Neoadjuvant } \\
\text { chemotherapy }\end{array}$} \\
\hline Yes & $3.4 \% \pm 1.1 \%$ & 0.012 & 1 & 0.157 \\
\hline No & $1.6 \% \pm 0.9 \%$ & - & $0.63(0.33-1.19)$ & - \\
\hline \multicolumn{5}{|l|}{$\begin{array}{l}\text { Boost design } \\
\text { method }\end{array}$} \\
\hline Surgical scar & $5.4 \% \pm 1.7 \%$ & $<0.001$ & 1 & $<0.001$ \\
\hline CT-bed & $0.8 \% \pm 0.5 \%$ & - & $0.24(0.12-0.47)$ & - \\
\hline \multicolumn{5}{|l|}{$\begin{array}{l}\text { Preoperative } \\
\text { MRI }\end{array}$} \\
\hline Yes & $1.6 \% \pm 0.7 \%$ & 0.266 & 1 & 0.275 \\
\hline No & $2.9 \% \pm 0.9 \%$ & - & $1.46(0.73-2.92)$ & - \\
\hline
\end{tabular}

The 8-year LR rates were 5.1\% (95\% CI, 3.6-6.4\%) during the period $1999-2007$ and $0.8 \%(95 \% \mathrm{CI}$, $0.3-1.3 \%$ ) during the period 2007-2011. The data on 8 -year LR rates by treatment year were 5.6\% (95\% CI, $3.5-7.7 \%)$ during the period $1999-2005,5.5 \%$ (95\% CI, 2.6-8.4\%) during 2006, 0.7\% (95\% CI, 0-1.6\%) during $2007,1.4 \%$ (95\% CI, 0.1-2.7\%) during 2008, 1.1\% (95\% CI, $0-2.2 \%$ ) during 2009 and $1.7 \%$ (95\% CI, $0.4-3.0 \%)$ during 2010.

We also performed univariate and multivariate analyses of various clinical, pathological, and treatment factors to identify predictors of IBTR. Lymph node involvement, a HER2-positive status, and the use of CT information during boost field planning were found to be independent predictors of IBTR (Table 3). However, age and the NAC were not independent predictors of either LR or IBTR. 


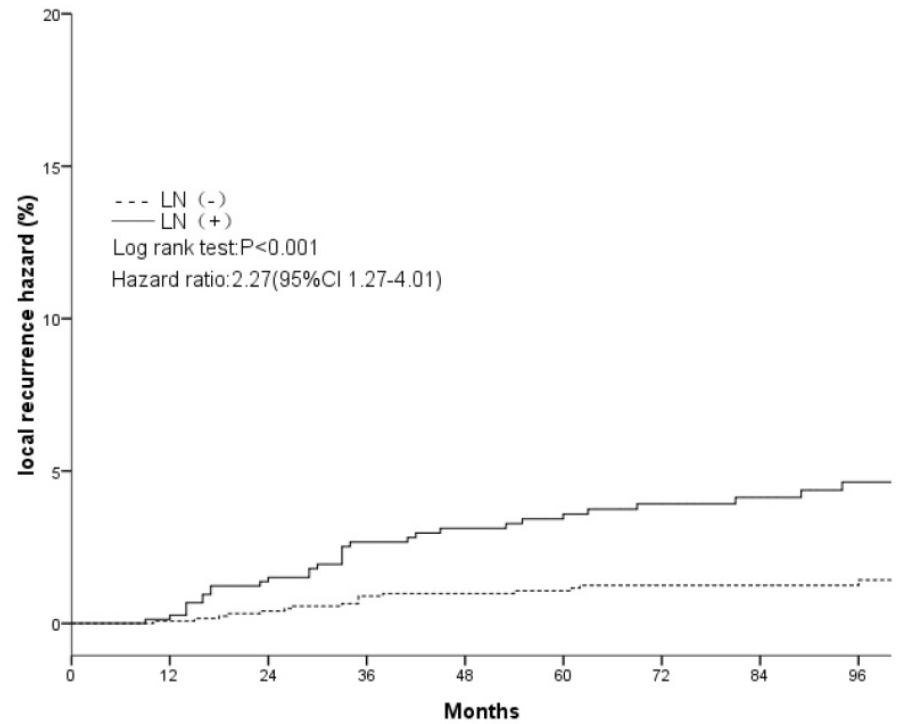

Figure 1. Local recurrence hazard related to axillary lymph nodes.

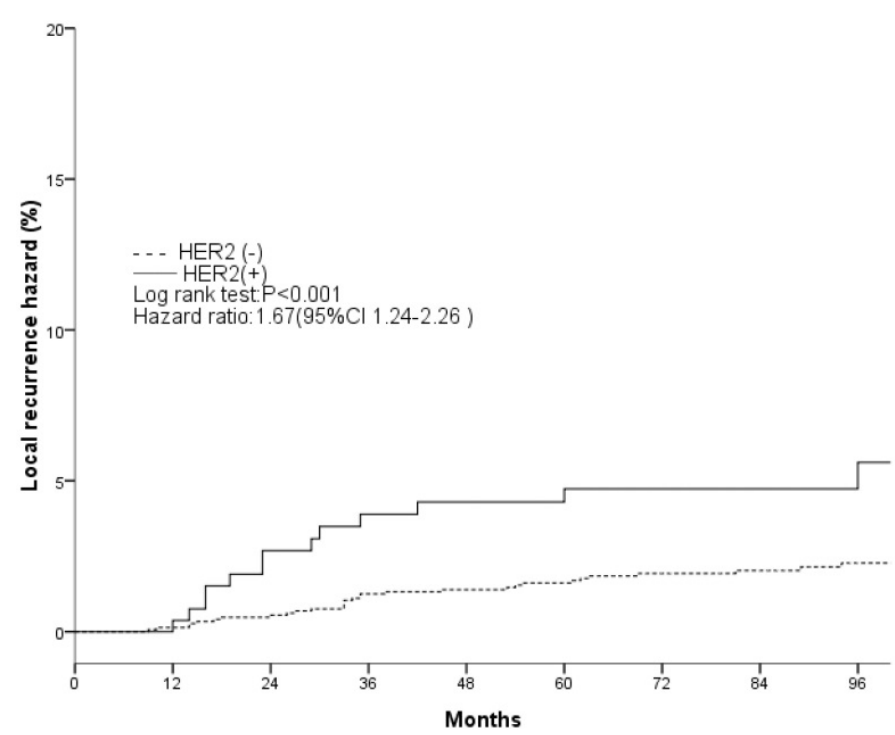

Figure 2. Local recurrence hazard related to HER2.

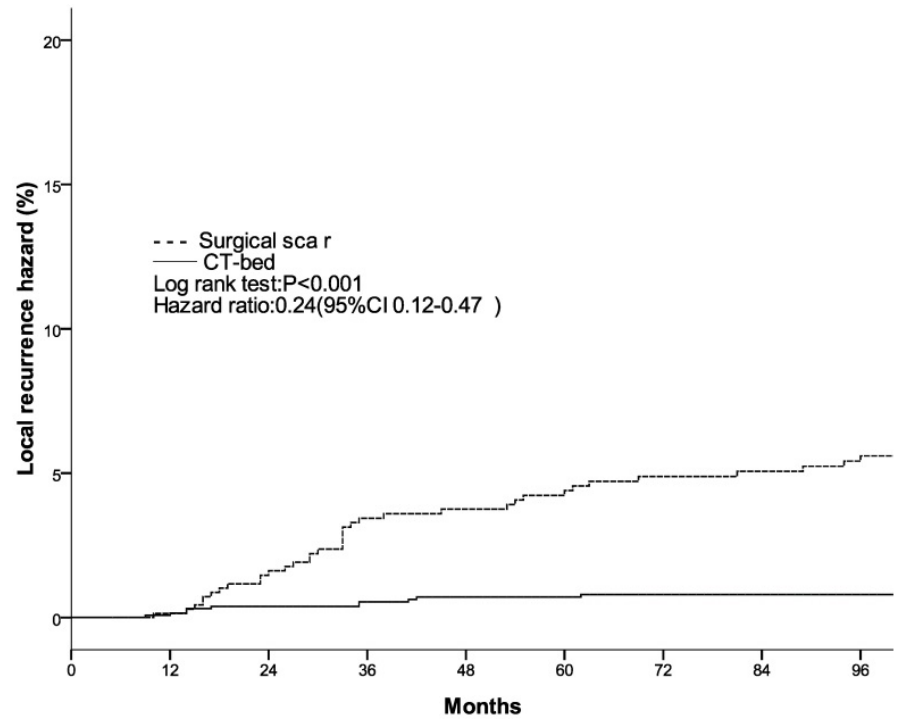

Figure 3. Local recurrence hazard related to method determining tumor bed. 
Table 3. Univariate and multivariable analysis for ipsilateral breast tumor recurrence (IBTR)

\begin{tabular}{|c|c|c|c|c|}
\hline \multirow[t]{2}{*}{ Factors } & \multicolumn{2}{|l|}{ Univariate analysis } & \multicolumn{2}{|c|}{ Multivariate analysis } \\
\hline & 8-year IBTR rate & $P^{*}$ & $H R^{* *}(95 \% \mathrm{CI})$ & $P^{* * *}$ \\
\hline \multicolumn{5}{|l|}{ Age (years) } \\
\hline$\leq 40$ & $3.8 \% \pm 1.7 \%$ & 0.182 & 1 & 0.206 \\
\hline$>40$ & $2.8 \% \pm 0.9 \%$ & - & $0.70(0.41-1.21)$ & - \\
\hline \multicolumn{5}{|l|}{ Size $(\mathrm{cm})$} \\
\hline$\leq 2$ & $2.0 \% \pm 0.7 \%$ & 0.020 & 1 & 0.101 \\
\hline$>2$ & $4.6 \% \pm 1.5 \%$ & - & $1.53(0.91-2.55)$ & - \\
\hline \multicolumn{5}{|l|}{$\begin{array}{l}\text { Hormone } \\
\text { receptor }\end{array}$} \\
\hline Negative & $4.6 \% \pm 1.9 \%$ & 0.102 & 1 & 0.277 \\
\hline Positive & $2.9 \% \pm 0.9 \%$ & - & $0.74(0.43-1.27)$ & - \\
\hline \multicolumn{5}{|l|}{$\begin{array}{l}\text { Axillary } \\
\text { lymph node }\end{array}$} \\
\hline Negative & $1.6 \% \pm 0.7 \%$ & $<0.001$ & 1 & 0.002 \\
\hline Positive & $5.4 \% \pm 1.7 \%$ & - & $2.29(1.36-3.86)$ & - \\
\hline \multicolumn{5}{|l|}{ Her-2 status } \\
\hline Negative & $2.8 \% \pm 0.9 \%$ & 0.001 & 1 & 0.002 \\
\hline Positive & $6.0 \% \pm 3.1 \%$ & - & $1.56(1.18-2.05)$ & - \\
\hline \multicolumn{5}{|l|}{$\begin{array}{l}\text { Neoadjuvant } \\
\text { chemotherapy }\end{array}$} \\
\hline Yes & $3.8 \% \pm 1.1 \%$ & 0.013 & 1 & 0.484 \\
\hline No & $2.1 \% \pm 0.9 \%$ & - & $0.80(0.44-1.46)$ & - \\
\hline \multicolumn{5}{|l|}{$\begin{array}{l}\text { Boost design } \\
\text { method }\end{array}$} \\
\hline Surgical scar & $6.1 \% \pm 1.7 \%$ & $<0.001$ & 1 & $<0.001$ \\
\hline CT-bed & $1.1 \% \pm 0.5 \%$ & - & $0.34(0.19-0.61)$ & - \\
\hline \multicolumn{5}{|l|}{$\begin{array}{l}\text { Preoperative } \\
\text { MRI }\end{array}$} \\
\hline Yes & $2.8 \% \pm 1.1 \%$ & 0.368 & 1 & 0.362 \\
\hline No & $3.3 \% \pm 1.1 \%$ & - & $1.33(0.71-2.49)$ & - \\
\hline
\end{tabular}

Table 4. Univariate and multivariable analysis for distant disease-free survival (DDFS)

\begin{tabular}{|c|c|c|c|c|}
\hline \multirow[t]{2}{*}{ Factors } & \multicolumn{2}{|l|}{ Univariate analysis } & \multicolumn{2}{|c|}{ Multivariate analysis } \\
\hline & 8-year DDFS rate & $P^{*}$ & $H R^{* *}(95 \% \mathrm{CI})$ & $P^{* * * *}$ \\
\hline \multicolumn{5}{|c|}{ Age (years) } \\
\hline$\leq 40$ & $90.4 \% \pm 2.7 \%$ & $<0.001$ & 1 & 0.013 \\
\hline$>40$ & $94.9 \% \pm 1.1 \%$ & - & $0.60(0.41-0.90)$ & - \\
\hline \multicolumn{5}{|c|}{$\begin{array}{l}\text { Axillary } \\
\text { lymph node }\end{array}$} \\
\hline Negative & $96.7 \% \pm 0.9 \%$ & $<0.001$ & 1 & $<0.001$ \\
\hline Positive & $88.9 \% \pm 2.3 \%$ & - & $3.12(2.05-4.72)$ & - \\
\hline \multicolumn{5}{|c|}{$\begin{array}{l}\text { Neoadjuvant } \\
\text { chemotherapy }\end{array}$} \\
\hline Yes & $92.0 \% \pm 1.7 \%$ & $<0.001$ & 1 & 0.072 \\
\hline No & $95.9 \% \pm 1.3 \%$ & - & $0.67(0.43-1.03)$ & - \\
\hline
\end{tabular}

\section{DDFS and DFS}

The above-mentioned multivariate analysis also identified the nodal status, age at diagnosis, and NAC as factors significantly affecting the 8-year DDFS rate (Table 4). Although the age at diagnosis was not an independent predictor of LR, it was identified as an independent predictor of DDFS in both univariate and multivariate analyses ( $\mathrm{HR}$ of $>40$ vs. $\leq 40$ years, 0.60 ; 95\% CI, 0.41-0.90; $P=0.013$ ). Finally, the age at diagnosis, $\mathrm{T}$ stage, lymph node involvement, HER2-positive status, and use of CT information during boost field planning were identified as independent predictors of DFS (Table 5).
Table 5. Univariate and multivariable analysis for disease-free survival (DFS)

\begin{tabular}{|c|c|c|c|c|}
\hline \multirow[t]{2}{*}{ Factors } & \multicolumn{2}{|c|}{ Univariate analysis } & \multicolumn{2}{|c|}{ Multivariate analysis } \\
\hline & 8-year DFS rate & $P^{*}$ & $H R^{* *}(95 \% \mathrm{CI})$ & $P^{* * *+}$ \\
\hline \multicolumn{5}{|l|}{ Age (years) } \\
\hline$\leq 40$ & $88.0 \% \pm 2.9 \%$ & 0.001 & 1 & 0.016 \\
\hline$>40$ & $92.5 \% \pm 1.3 \%$ & - & $0.66(0.47-0.92)$ & - \\
\hline \multicolumn{5}{|l|}{ Size $(\mathrm{cm})$} \\
\hline$\leq 2$ & $93.9 \% \pm 1.3 \%$ & $<0.001$ & 1 & 0.006 \\
\hline$>2$ & $87.5 \% \pm 2.3 \%$ & - & $1.56(1.13-2.15)$ & - \\
\hline \multicolumn{5}{|l|}{$\begin{array}{l}\text { Axillary } \\
\text { lymph node }\end{array}$} \\
\hline Negative & $95.2 \% \pm 1.1 \%$ & $<0.001$ & 1 & $<0.001$ \\
\hline Positive & $85.0 \% \pm 2.7 \%$ & - & $2.69(1.93-3.76)$ & - \\
\hline \multicolumn{5}{|l|}{ Her-2 status } \\
\hline Negative & $91.7 \% \pm 1.5 \%$ & 0.013 & 1 & 0.011 \\
\hline Positive & $87.8 \% \pm 4.1 \%$ & - & $1.28(1.05-1.54)$ & - \\
\hline \multicolumn{5}{|l|}{$\begin{array}{l}\text { Boost design } \\
\text { method }\end{array}$} \\
\hline Surgical scar & $87.3 \% \pm 2.5 \%$ & $<0.001$ & 1 & 0.010 \\
\hline CT-bed & $93.8 \% \pm 1.3 \%$ & - & $0.65(0.47-0.90)$ & - \\
\hline
\end{tabular}

${ }^{*} P<0.05$ is deemed statistically significant (log-rank test); ${ }^{* *} H R$ : hazard ratio; ${ }^{* * *} P$ $<0.1$ is deemed statistically significant.

\section{Discussion}

In this study of the associations of BCT with 8-year outcome rates determined using the Kaplan-Meier method, we determined a LR rate of $2.6 \%$ and IBTR rate of $3.0 \%$, which are consistent with those reported in other contemporary series $[1,2,6]$. Furthermore, we found that the use of CT data during boost field planning significantly reduced the risk of LR. We observed a 5-year LR rate of $0.7 \%$ between 2007 and 2011, which was superior to the results reported by the TARGIT-A trial (5-year risk of conserved breast LR in the control group $=1.3 \%$ [0.7\%-2.5\%]) [7]. Additionally, we observed a decreasing trend in the LR rate after $\mathrm{BCT}$ during the study period; this rate remained at $0.7 \%$ annually for patients treated during 1999-2007 and decreased to $0.1 \%$ annually during the period 2007-2011. LR rate decreased significantly on 2007. The rates were stable within post-2007 groups. Interestingly, 32.1\% of patients in this study received BCT. This is among the highest rates of $\mathrm{BCT}$ among studies of Chinese patients.

In a previous study, radiotherapy after BCS not only substantially reduced the risk of recurrence, but also moderately reduced the risk of death from breast cancer [6]. However, postoperative breast changes and remodeling present a challenge to the localization of the tumor bed. Accordingly, many centers currently use CT-based planning for breast radiotherapy [8-10]. CT scans also provide information regarding the placement of the boost field. In most cases, the excision cavity can be visualized. The depth, therefore the electron beam energy, can be determined. This study further confirmed a significant association of the use of CT information during boost field planning with LR. In 
this study, volume replacement techniques based on glandular reshaping were applied to patients to obtain better cosmetic outcomes. The use of the surgical scar to determine the tumor bed and, therefore, the boost field may yield poor outcomes, as this can result in geographical misses and lead to increased local failure rates. Although a European Organisation for Research and Treatment of Cancer (EORTC) trial reported a decreased risk of IBTR in patients who received the boost dose, no differences in survival were observed between patients who received and did not receive a boost of 16 Gy after whole-breast irradiation [11]. In the present study, we found that the use of $\mathrm{CT}$ information during boost field planning did not lead to a reduction in distant recurrence. The findings of an earlier Early Breast Cancer Trialists' Collaborative Group (EBCTCG) meta-analysis showed that unless the difference in LR was $10 \%$, there was no difference in OS [6]. The findings of this report are consistent with the EBCTCG. $37.4 \%$ of patients in the present study were node positive. We note that the EBCTCG trial specifically reported the survival benefit of radiotherapy in node-positive patients.

NAC is widely accepted as a treatment for advanced operable breast cancer, as it can reduce the size of the primary tumor and therefore increase the likelihood of successfully completing a BCS in patients advised to undergo a mastectomy [12, 13]. Two large randomized trials, National Surgical Adjuvant Breast and Bowel Project (NSABP) B-18 and EORTC 10902, compared preoperative chemotherapy with postoperative chemotherapy in patients with operable breast cancer. Both trials reported equivalent survival rates between the arms, as well as increased rates of BCS performance following preoperative chemotherapy $[12,13]$. In our analysis, we did not identify NAC as an independent predictor of LR. Patients with a more advanced clinical $\mathrm{T}$ stage or a node-positive status at diagnosis were generally encouraged by oncologists to receive NAC and were considered to have a worse biologic entity. We further found that neoadjuvant treatment was associated with a higher relative risk of DDFS, compared to adjuvant treatment. However, we cannot explain the effect of a pathological response on LR in this study because the pathological response after NAC was not evaluated. Mittendorf et al. reported no difference in the LR rates between patients undergoing surgery first vs. those treated with NAC [14], while a meta-analysis by Mieog et al. demonstrated a non-significant increase in the local relapse rate in the NAC group, compared with the adjuvant therapy group [15]. A recent study reported a higher LR rate among patients who underwent NAC than among those treated with surgery first, as well as a potential association of tumor downstaging by NAC with an increased risk of LR after BCS [5]. However, the meta-analysis was biased by the inclusion of patients who did not receive optimal local treatment after NAC [5]. Tumor resection with a clear margin and an acceptable cosmetic result requires sufficient shrinkage of the tumor via NAC. However, the current methods used to assess tumor shrinkage patterns preoperatively are inadequate. In the present study, the entire area of the original primary tumor was resected after NAC, although this practice is not considered necessary by the St. Gallen Expert Consensus Panel [16].

Many previous studies on BCT have identified an increased risk of local relapse in younger women, compared with older women [17, 18]. However, limited data are available from Chinese women. Our findings demonstrated showed that the rate of local relapse after BCT did not differ between young $(\leq 40$ years) and older (>40 years) women, and similar results were obtained from the comparisons of other dichotomized age groups. These findings are not consistent with those of earlier trials $[6,17,18]$.

In previous studies, the administration of anti-HER2 therapy has yielded significant survival advantages when administered to early breast cancer patients with or after chemotherapy, compared to observation alone $[19,20]$. In the present study, however, only a few patients could afford trastuzumab treatment. Therefore, a HER2-positive status remained an independent predictor of LR and IBTR.

A previous report found that the inclusion of MRI in a preoperative assessment did not improve surgical treatment outcomes or reduce the risk of re-excision [21], and a meta-analysis demonstrated that preoperative MRI for breast cancer staging did not reduce the risk of LR [22]. At our center, we first integrated MRI into practice for the staging of newly diagnosed breast cancer in January 2007. Consistent with earlier reports, the present study found no association of preoperative MRI with a reduced risk of LR or an improved DFS. We note that MRI is mainly used to determine the conversion from BCS to mastectomy; in other words, this imaging modality increases the risk of a more intensive therapeutic surgery [22-24]. Although MRI can detect previously unrecognized but pathologically confirmed cancer deposits, these lesions may be biologically and clinically irrelevant in a patient who is expected to undergo standard excision and breast irradiation.

Veronesi et al. reported that the characteristics of true recurrences (TR) were consistent with the regrowth of malignant cells not removed by surgery 
or killed by radiotherapy [25]. According to previous studies, the locations of the first and second tumors, histological subtypes and time to relapse were used to classify TR or new primary breast cancers (NP) [26]. Some studies have suggested an association of TR with reduced survival relative to NP [26- 29]. Some molecular techniques such as DNA fingerprinting, loss of heterozygosity patterning, or allelic imbalance profiling have been used to distinguish NP from TR [30]. However, the classifications for these techniques have not been standardized.

There are several limitations in our study. First, a retrospective study has inherent bias and weakness. This study showed a non-significant increase in the local relapse rate in the NAC group and was unable to prove equivalent LR adequately. Second, CT-guidance was one of factors improving result, and other treatment factors may be not concerned in this retrospective study. Third, detailed data about extent or frequency of re-shaping were not available which were rarely recorded in previous operation notes. It is possible that the group for whom CT is useful is restricted to those undergoing re-shaping. We will improve the operation notes and do further research about this issue in future.

In conclusion, this retrospective study indicates that the use of CT information during boost field planning could reduce the risk of LR in patients undergoing BCT. However, the administration of NAC vs. adjuvant treatment did not significantly affect LR. Moreover, BCT is effective for local tumor control when performed in younger Chinese patients ( $\leq 40$ years old).

\section{Competing Interests}

The authors have declared that no competing interest exists.

\section{References}

1. Veronesi U, Cascinelli N, Mariani L, et al. Twenty-year follow-up of a randomized study comparing breast-conserving surgery with radical mastectomy for early breast cancer. N Engl J Med. 2002, 347: 1227-32. doi: 10.1056/NEJMoa020989.

2. Fisher B, Anderson S, Bryant J, et al. Twenty-year follow-up of a randomized trial comparing total mastectomy, lumpectomy, and lumpectomy plus irradiation for the treatment of invasive breast cancer. N Engl J Med. 2002, 347:1233-1241. doi: 10.1056/NEJMoa022152.

3. van Maaren MC, de Munck L, Jobsen JJ, et al. Breast-conserving therapy versus mastectomy in T1-2N2 stage breast cancer: a population-based study on 10-year overall, relative, and distant metastasis-free survival in 3071 patients. Breast Cancer Res Treat. 2016, 160(3): 511-521. doi: 10.1007/s10549-016-4012-8.

4. Wang L, Ouyang T, Wang T, et al. Breast-conserving therapy and modified radical mastectomy for primary breast carcinoma: a matched comparative study. Chin J Cancer Res. 2015, 27 (6):545-52. doi: 10.3978/j.issn.1000-9604.2015.11.02.

5. Early Breast Cancer Trialists' Collaborative Group (EBCTCG). Long-term outcomes for neoadjuvant versus adjuvant chemotherapy in early breast cancer: meta-analysis of individual patient data from ten randomised trials. Lancet Oncol, 2018, 19: 27-39. doi: 10.1016/S1470-2045(17)30777-5.

6. Early Breast Cancer Trialists' Collaborative Group (EBCTCG). Effect of radiotherapy after breast-conserving surgery on 10-year recurrence and 15-year breast cancer death: meta-analysis of individual patient data for 10801 women in 17 randomised trials. Lancet. 2011, 378: 1707-16. doi: 10.1016/S0140-6736(11)61629-2.

7. Vaidya JS, Frederik Wenz, Max Bulsara, et al. Risk-adapted targeted intraoperative radiotherapy versus whole-breast radiotherapy for breast cancer: 5-year results for local control and overall survival from the TARGIT-A randomised trial. Lancet 2014, 383: 603-613. doi: 10.1016/S0140-6736(13)61950-9.

8. Weed D, Wong J, Yan D, et al. The validity of clips as a radiographic surrogate for the biopsy cavity in image-guided accelerated partial breast irradiation. Int J Radiat Oncol Biol Phys. 2004, 60 (2):484-92. doi: 10.1016/j.ijrobp.2004.03.012.

9. Bentel G, Marks LB, Hardenbergh P, et al. Variability of the location of internal mammary vessels and glandular breast tissue in breast cancer patients undergoing routine CT-based treatment planning. Int J Radiat Oncol Biol Phys 1999, 44(5):1017-25.

10. Kirova YM, Fournier-Bidoz N, Servois V, et al. How to boost the breast tumor bed? A multidisciplinary approach in eight steps. Int J Radiat Oncol Biol Phys. 2008, 72(2): 494-500. doi: 10.1016/j.ijrobp.2007.12.059.

11. Harry Bartelink, Philippe Maingon, Philip Poortmans, et al. Whole-breast irradiation with or without a boost for patients treated with breast-conserving surgery for early breast cancer: 20-year follow-up of a randomised phase 3 trial. Lancet Oncol. 2015, 16: 47-56. doi: 10.1016/S1470-2045(14)71156-8.

12. Van der Hage JA, van de Velde CJ, Julien JP, Tubiana-Hulin M, et al. Preoperative chemotherapy in primary operable breast cancer: results from the European Organization for Research and Treatment of Cancer trial 10902. J Clin Oncol. 2001, 19 : 4224- 4237. doi: 10.1200/JCO.2001.19.22.4224.

13. Wolmark N, Wang J, Mamounas E, Bryant J, Fisher B. Preoperative chemotherapy in patients with operable breast cancer: nine-year results from National Surgical Adjuvant Breast and Bowel Project B-18. J Natl Cancer Inst Monogr. 2001, (30): 96-102.

14. Mittendorf EA, Buchholz TA, Tucker SL, et al. Impact of chemotherapy sequencing on local-regional failure risk in breast cancer patients undergoing breast-conserving therapy. Ann Surg. 2013, 257(2):173-179. doi: 10.1097/SLA.0b013e3182805c4a.

15. Mieog J. S., van der Hage J. A., van de Velde C. J. Neoadjuvant chemotherapy for operable breast cancer. Br. J. Surg. 2007, 94, 1189-1200. doi: $10.1002 /$ bjs.5894.

16. Coates AS, Winer EP, Goldhirsch A, et al. Tailoring therapies-improving the management of early breast cancer: St Gallen International Expert Consensus on the Primary Therapy of Early Breast Cancer 2015. Ann Oncol. 2015, 8:1533-46. doi: 10.1093/annonc/mdv221.

17. Jones HA, Antonini N, Hart AA, et al. Impact of pathological characteristics on local relapse after breast-conserving therapy: a subgroup analysis of the EORTC boost versus no boost trial. J Clin Oncol. 2009, 27(30): 4939-47. doi: 10.1200/JCO.2008.21.5764.

18. Marloes van der Leest, Lisette Evers, Maurice J. C. van der Sangen, et al. The safety of breast-conserving therapy in patients with breast cancer aged $\leqslant 40$ years. Cancer 2007, 109: 1957-64. doi: 10.1002/cncr.22639.

19. Perez EA, Romond EH, Suman VJ, et al. Trastuzumab plus adjuvant chemotherapy for human epidermal growth factor receptor 2-positive breast cancer: planned joint analysis of overall survival from NSABP B-31 and NCCTG N9831. J Clin Oncol 2014; 32:3744-52. doi: 10.1200/JCO.2014.55.5730.

20. Gianni L, Dafni U, Gelber RD, et al. Treatment with trastuzumab for 1 year after adjuvant chemotherapy in patients with HER2-positive early breast cancer: a 4-year follow-up of a randomised controlled trial. Lancet Oncol 2011; 12:236-44. doi: 10.1016/S1470-2045(11)70033-X

21. Houssami N, Ciatto S, Macaskill P, et al. Accuracy and surgical impact of magnetic resonance imaging in breast cancer staging: Systematic review and meta-analysis in detection of multifocal and multicentric cancer. J Clin Oncol. 2008, 26:3248-3258. doi: 10.1200/JCO.2007.15.2108.

22. Houssami N, Turner R, Macaskill P, et al. An individual person data meta-analysis of preoperative magnetic resonance imaging and breast cancer recurrence. J Clin Oncol. 2014, 32: 392-401. doi: 10.1200/JCO.2013.52.7515.

23. Houssami N, Turner R and Monica Morrow. Preoperative magnetic resonance imaging in breast cancer meta-analysis of surgical outcomes. Ann Surg. 2013, 257: 249-255. doi: 10.1097/SLA.0b013e31827a8d17.

24. Houssami N and Hayes DF. Review of preoperative magnetic resonance imaging (MRI) in breast cancer: Should MRI be performed on all women with newly diagnosed, early stage breast cancer? CA Cancer J Clin. 2009, 59:290-302. doi: 10.3322/caac.20028.

25. Veronesi U, Marubini E, Del Vecchio M, et al. Local recurrences and distant metastases after conservative breast cancer treatments: partly independent events. J Natl Cancer Inst. 1995, 87(1):19-27.

26. Huang E, Buchholz TA, Meric F, et al. Classifying local disease recurrences after breast conservation therapy based on location and histology: new primary tumors have more favorable outcomes than true local disease recurrences. Cancer. 2002, 95(10):2059-67. doi: 10.1002/cncr.10952.

27. Nishimura S, Takahashi K, Akiyama F, et al. Classification of ipsilateral breast tumor recurrence after breast-conserving therapy: new primary cancer allows a good prognosis. Breast Cancer. 2005, 12(2):112-7.

28. Komoike Y, Akiyama F, lino Y, et al. Analysis of ipsilateral breast tumor recurrences after breast-conserving treatment based on the classification of true recurrences and new primary tumors. Breast Cancer. 2005, 12(2):104-11.

29. Panet-Raymond V, Truong PT, McDonald RE, et al. True recurrence versus new primary: an analysis of ipsilateral breast tumor recurrences after 
breast-conserving therapy. Int J Radiat Oncol Biol Phys. 2011, 81(2):409-17. doi: 10.1016/j.jijrobp.2010.05.063.

30. Schlechter BL, Yang Q, Larson PS, et al. Quantitative DNA fingerprinting may

distinguish new primary breast cancer from disease recurrence. J Clin Oncol. 2004, 22(10):1830-8. doi: 10.1200/JCO.2004.05.123. 